\title{
Extended Morphological Profile Cube for Hyperspectral Image Classification
}

This paper was downloaded from TechRxiv (https://www.techrxiv.org).

\section{LICENSE}

CC BY 4.0

SUBMISSION DATE / POSTED DATE

08-05-2021 / 13-05-2021

CITATION

DIAKITE, ALOU; JIANGSHENG, GUI; XIAPING, FU (2021): Extended Morphological Profile Cube for Hyperspectral Image Classification. TechRxiv. Preprint. https://doi.org/10.36227/techrxiv.14560848.v1

$\mathrm{DOI}$

10.36227/techrxiv.14560848.v1 
Existing methods used large training samples can lead to overfitting
Traditional methods I

Deep learning

Low classification result

\section{EMPC}

$+$

3D Densenet
Proposed methods used small training samples

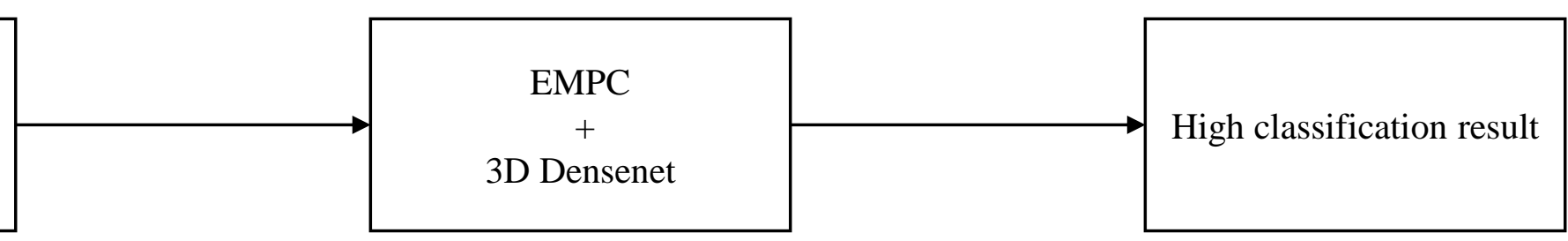

